\title{
Levothyroxine and lung cancer in females: the importance of oxidative stress
}

\author{
Umberto Cornelli ${ }^{1}$, Gianni Belcaro ${ }^{2}$, Martino Recchia ${ }^{3}$ and Annarosa Finco ${ }^{4 *}$
}

\begin{abstract}
Background: Levothyroxine $\left(\mathrm{LT}_{4}\right)$ treatment can lead to iatrogenic hyperthyroidism and oxidative stress that can cause patient discomfort. Oxidative stress is also recognized as one of the causes of chronic diseases and cancer.

Methods: The prevalence of breast, colorectal, gastric and lung cancer in 18 Italian Regions during 2010 was correlated with the sales of $\mathrm{LT}_{4}$ in 2009. The cancer prevalence was analyzed in women aged 30-84. This age range corresponds to more than $80 \%$ of the consumers of the drug and to about $99 \%$ of all malignant cancers. The correlation between sales of $\mathrm{LT}_{4}$ and cancers was determined with the technique of Density Ellipses. The age and smoking contribution for lung cancer was determined with the Sequential test.

Results: No significant correlation was seen between $\mathrm{LT}_{4}$ sales and breast, colorectal and gastric cancers. A significant correlation was instead found for lung cancer $(p<0.05)$ corrected for smoking and age.

Conclusions: $\mathrm{LT}_{4}$ consumption in Italy is about 0.7 boxes/women/year. There is a correlation between lung cancer and $\mathrm{LT}_{4}$ treatment and oxidative stress caused by $\mathrm{LT}_{4}$ supplementation can be one of the causes. Although we cannot exclude that dysthyroidism needing $\mathrm{LT}_{4}$ supplementation might be the ground for lung cancer itself and measuring oxidative stress could be helpful in avoiding excessive use of the drug.
\end{abstract}

Keywords: Levothyroxine, Smoking, Oxidative stress, Lung cancer, Dysthyroidism

\section{Background}

During studies aimed at assessing the relationship between food intake and metabolic syndrome in Italy, a large number of subjects was found to use levothyroxine $\left(\mathrm{LT}_{4}\right)$ for hypothyroidism.

A survey conducted in USA on the intake of thyroid supplements [1] found that side effects may occur in as many as $20 \%$ of treated cases, the most common being palpitation, sweating, agitation/anxiety and daily discomfort which are typical symptoms of iatrogenic hyperthyroidism.

A clinical study indicated that these side effects were correlated with the increase of plasma hydroperoxides which are markers of oxidative stress [2], and the use of a pool of physiological modulators (PMs) with antioxidant activity was found effective in reducing all these side effects [3].

\footnotetext{
* Correspondence: finco.annarosa@libero.it

${ }^{4}$ Cor Con International-Ox Res Dept, Parma(PR), Italy

Full list of author information is available at the end of the article
}

These findings suggest that the chronic use of $\mathrm{LT}_{4}$ is consistent with an overproduction of reactive oxygen species (ROS) caused by the hypermetabolic status provoked by administration of this hormone [4-6].

Achievement of euthyroid status is monitored by measuring TSH, $\mathrm{T}_{3}$ and $\mathrm{T}_{4}$ plasma levels, mainly in the morning on a empty stomach, a few times in a year, but measuring oxidative stress was never considered a useful tool for adjusting $\mathrm{LT}_{4}$ doses. The $\mathrm{LT}_{4}$ administration leads to $\mathrm{T}_{4}$ and $\mathrm{T}_{3}$ peak between one and two hours after the drug is taken $[7,8]$. These peaks triggers an increase of plasma hydroperoxides which is reduced by the administration of physiological modulators with antioxidant activity $[2,3]$.

The aim of the present research was to correlate the $\mathrm{LT}_{4}$ as a chronic oxidative stress generator with the prevalence of four different types of tumors: breast, colorectal, gastric and lung in 18 Italian Regions. Since more than $80 \%$ of supplement prescriptions of the supplement are made out to women, the correlation between $\mathrm{LT}_{4}$ sales and cancers was calculated for females only.

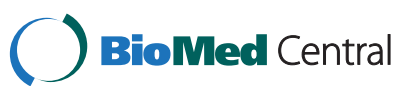




\section{Methods}

Data on $\mathrm{LT}_{4}$ sales, sales in pharmacy in 18 Italian regions in 2009 and 2010, were provided by IMS (Intercontinental Marketing Service). These data were correlated with the prevalence of breast, colorectal, gastric and lung cancers in females in the same regions.

The IMS sex distribution and age group data show that $83.5 \%$ of the $\mathrm{LT}_{4}$ prescriptions were made out to females, and $94.4 \%$ were to patients aged more than 30 years. Public data on cancer incidence, prevalence and mortality in Italy can be obtained on line and are reported by type of cancer, sex/age/Region (www.tumori. net). The raw prevalence data (number of cases $/ 100,000$ inhabitants) in the of 30-84 years age group was taken and correlated with the drug sales, regardless of the different doses used.

Smoking prevalence was obtained by Istat.it (www. istat.it) from and the relative sex distribution from OSSFAD (Osservatorio Fumo Alcol e Droga Istituto Superiore di Sanità- report May 31, 2010). The average prevalence between 2007 to 2009 in the 18 Italian Regions was taken for the evaluation because data before 2007 were not available for all Regions. Aging index was taken by Istat.it.

\section{Statistical methods}

The continuous variables "prevalence" and "sales $\mathrm{LT}_{4}$ " were analyzed by correlation analysis with the technique of Density Ellipse [9]. The correlations analysis yields only one number, an index designed to give an immediate picture of how closely two variables move together, while the ellipse represents all combinations of $\mathrm{X}$ and $\mathrm{Y}$ with the same probability density. It is called an isoprobability curve. The straight line represents the axis common to all these level curves. If the bivariate normal distribution concentrates about this major axis, $\rho$ has a higher numerical value. These ellipses are both density contours and confidence curves. As confidence curves, they show where a given percentage of the data is expected to lie, assuming the bivariate normal distribution. The densities of the ellipse were drawn with $\mathrm{p}=0.90$.

In case of correlation between $\mathrm{LT}_{4}$ and cancer the Multiple Regression Analysis was applied followed by the Sequential test (or type ISS) to highlight the contribution of single variables (aging, smoke and $\mathrm{LT}_{4}$ treatment).

The statistical analysis applied to data is a multiple regression model with the stepwise specification. The Stepwise feature computes estimates that are the same as those of other least squares platforms, but it facilitates searching and selecting among many models. Sequential Tests show the reduction in residual sum of squares as each effect is entered into the fit. The sequential tests are also called Type I sums of squares (Type I SS). A desirable property of the Type I SS is that they are independent and sum to the regression SS.

\section{Results}

The Italian females population aged between 30 and 84 years was estimated to be about 19.89 million in 2010 (http://dati.istat.it/) and the relevant sales of $\mathrm{LT}_{4}$ in 2009 amounts to 13.93 million boxes (total sales 16.68 million boxes without considering the different dosages) corresponding to a yearly consumption of 0.7 boxes/woman.

The data concerning the different cancers, smoking and aging index are reported in Table 1.

The correlation between smoking and the four cancers (data not reported) was statistically significant for lung cancer only $(p<0.05)$ while for all the other type of cancer was practically inconsistent.

The aging index was shown to be significant for colorectal cancer only $(\mathrm{p}<0.05)$ and not for all the other type of cancer (data not reported).

For what concern the correlation between sales of $\mathrm{LT}_{4}$ and cancers the data are reported in Figure 1 (A,B,C,D).

The prevalence sales ellipsis is relatively wide, which corresponds to no significant correlation.

The data concerning colorectal cancer and $\mathrm{LT}_{4}$ sales (Figure 1B) show that, for this type of tumor, there was no significant relationship and, like in the case of breast cancer, data were spread out over a large ellipsis.

The values of the relationship between sales and prevalence are also distributed over a wide area in the case of stomach cancer (Figure 1C).

A significant $(\mathrm{p}<0.05)$ correlation was found for lung cancer (Figure 1D).

Smoking is known to be related to lung cancer and to cause an over-fitting effect that hides the possible contribution of other variables such as aging and $\mathrm{LT}_{4}$. The sequential analysis applied to the data eliminated the effect of smoking and made evident the contribution of aging and $\mathrm{LT}_{4}$.

The results were that age do not contribute significantly to the development of lung cancer $(p=0.532)$ whereas $\mathrm{LT}_{4}$ is significantly related to lung cancer $(\mathrm{p}=$ 0.003).

A more evident differentiation can be drawn splitting smoking prevalence into three different age range 2544, 45-64, and 65-84 that was respectively 24.3, 25.9 and 7.4 (OSSFAD 2010 report May 31, 2010). This means that the smoking prevalence was reduced by three times in the last age range. The prevalence of $\mathrm{LT}_{4}$ use instead was respectively 18.6, 35.1 and 35.2, showing that in the two age ranges the drug consumption was identical whereas the lung cancer prevalence was respectively 8.1, 64.3 and 199.2. In other words, in the last range, to a drastic reduction of smoking $(-71 \%)$ was corresponding a sharp increase of lung cancer $(+300 \%)$. 
Table 1 Levothyroxine sales (number of boxes sold), raw prevalence of some cancer in females in 18 different Italian regions in 2010 in relation to the sales of $\mathrm{LT}_{4}$ in 2009; average smoking prevalence in women between 2007 and 2009

\begin{tabular}{|c|c|c|c|c|c|c|c|}
\hline \multirow[b]{2}{*}{ Area $^{\mathrm{a}}$} & \multicolumn{7}{|c|}{ Type of cancer and prevalence $\left(10^{5}\right)$ in females } \\
\hline & Sales $\mathrm{LT}_{4}^{\mathrm{b}}$ & Breast & Colorectal & Gastric & Lung & Smoking $^{c}$ & Aging index ${ }^{d}$ \\
\hline 1 & 1072879 & 3165.62 & 776.88 & 120.04 & 97.47 & 21.6 & 139.9 \\
\hline 2 & 1028179 & 3118.67 & 646.35 & 96.03 & 68.08 & 23.0 & 150.0 \\
\hline 3 & 267126 & 2669.96 & 714.53 & 199.34 & 100.45 & 26.5 & 180.5 \\
\hline 4 & 273291 & 3210.26 & 750.28 & 131.17 & 72.57 & 20.0 & 116.5 \\
\hline 5 & 1438397 & 1589.44 & 370.62 & 76.35 & 82.94 & 23.0 & 120.2 \\
\hline 6 & 1179775 & 2674.95 & 625.72 & 182.42 & 91.74 & 26.0 & 184.1 \\
\hline 7 & 487525 & 2250.40 & 416.66 & 55.21 & 62.85 & 20.0 & 154.8 \\
\hline 8 & 1087091 & 1418.33 & 374.09 & 87.74 & 60.79 & 22.0 & 122.1 \\
\hline 9 & 405995 & 1579.13 & 389.64 & 103.25 & 54.03 & 21.0 & 168,9 \\
\hline 10 & 408040 & 2722.42 & 716.09 & 198.61 & 84.07 & 23.0 & 168.7 \\
\hline 11 & 1879231 & 2909.03 & 733.82 & 174.65 & 77.41 & 29.0 & 141.9 \\
\hline 12 & 467753 & 2824.49 & 751.36 & 90.85 & 82.19 & 23.0 & 234.6 \\
\hline 13 & 2423825 & 2882.24 & 557.33 & 109.31 & 138.66 & 29.0 & 141.6 \\
\hline 14 & 287660 & 3424.94 & 837.82 & 162.56 & 116.44 & 23.1 & 187.4 \\
\hline 15 & 1474482 & 3269.15 & 815.26 & 169.85 & 94.09 & 26.0 & 170.0 \\
\hline 16 & 631585 & 1442.77 & 329.72 & 97.17 & 44.45 & 22.8 & 130.2 \\
\hline 17 & 1682805 & 1622.33 & 378.19 & 99.62 & 96.59 & 27.0 & 96.5 \\
\hline 18 & 183079 & 1474.73 & 430.39 & 100.85 & 45.98 & 16.0 & 148.2 \\
\hline
\end{tabular}

${ }^{a}$ 1-Veneto; 2-Piemonte-Valle d'Aosta; 3-Umbria; 4-Trentino Alto Adige; 5-Sicilia; 6-Toscana; 7-Sardegna; 8-Puglia; 9-Abruzzo-Molise; 10-Marche; 11-Lombardia; 12-Liguria; 13-Lazio; 14-Friuli Venezia Giulia; 15-Emilia Romagna; 16-Calabria; 17-Campania; 18-Basilicata;

${ }^{\text {b}}$ Sales of $\mathrm{LT}_{4}$, boxes regardless to different doses in 2009, data from IMSHealth-ITSSMS-Anno 2009;

caverage smoking prevalence from 2007 and 2009 ( $\times 100$ people);

${ }^{\mathrm{d}}$ Aging index in 2010.

Sales in 2010 were also compared with the prevalence of cancers in 2010 (instead of sales in 2009-data not reported), and the values were almost identical.

\section{Discussion}

The findings of this research suffer of many limitations due to type of data that analyzed.

For instance, the impossibility to determine the $\mathrm{LT}_{4}$ dosage does not allow dose/effect relationship to be looked into. In addition, the lack of sex distribution of the drug in the different regions, the nonexistence of a study protocol and a clinical record form to guide the study may limit further the data interpretation. However, 13.9 million boxes spread between 14 million women are very sizeable figures and may give important indications.

In this assessment no relationship was found between $\mathrm{LT}_{4}$ prescription and breast cancer among the Italian population.

The average prevalence measured in the regions of Southern of Italy (Sicilia, Puglia, Abruzzo/Molise, Calabria, Campania, Basilicata, Sardegna) was 1600.65 compared to value of 2998.59 in all the other regions. This difference could be due to Mediterranean diet, which is more widespread in Southern Italy and improves the AO capacity.
The relationship between oxidative stress and this type of cancer was examined in the Long Island Breast Cancer Study Project through the measurement of urinary isoprostane (15-isoprostane $\mathrm{F}_{2 \mathrm{t}}$ ) which mirrors oxidative stress due to lipid peroxidation [10]. A positive correlation was found between urinary isoprostrane levels and cancer, which underlines the importance of oxidative stress measurement.

It may be possible that the $\mathrm{AO}$ intake in the Southern regions of Italy have diluted the pro-oxidant effect of $\mathrm{LT}_{4}$ in all the country and made inconsistent the correlation between the two variables under study.

No correlation was found in our study between colorectal cancer and $\mathrm{LT}_{4}$ administration. A negative correlation with long term use of $\mathrm{LT}_{4}$ ( $<5$ years) was described in literature in a case-control study on colorectal cancer conducted in Northern Israel [11]; in the case of women, the effect was independent from the use hormone replacement therapy (HRT).

The prevalence of colorectal cancer in the regions of the Southern Italy was lower than in all the other Italy (376.43 and 704.92 respectively), and seems again to be consistent with the fact that the Mediterranean diet is more common in the South of Italy than in the other Italian regions. 


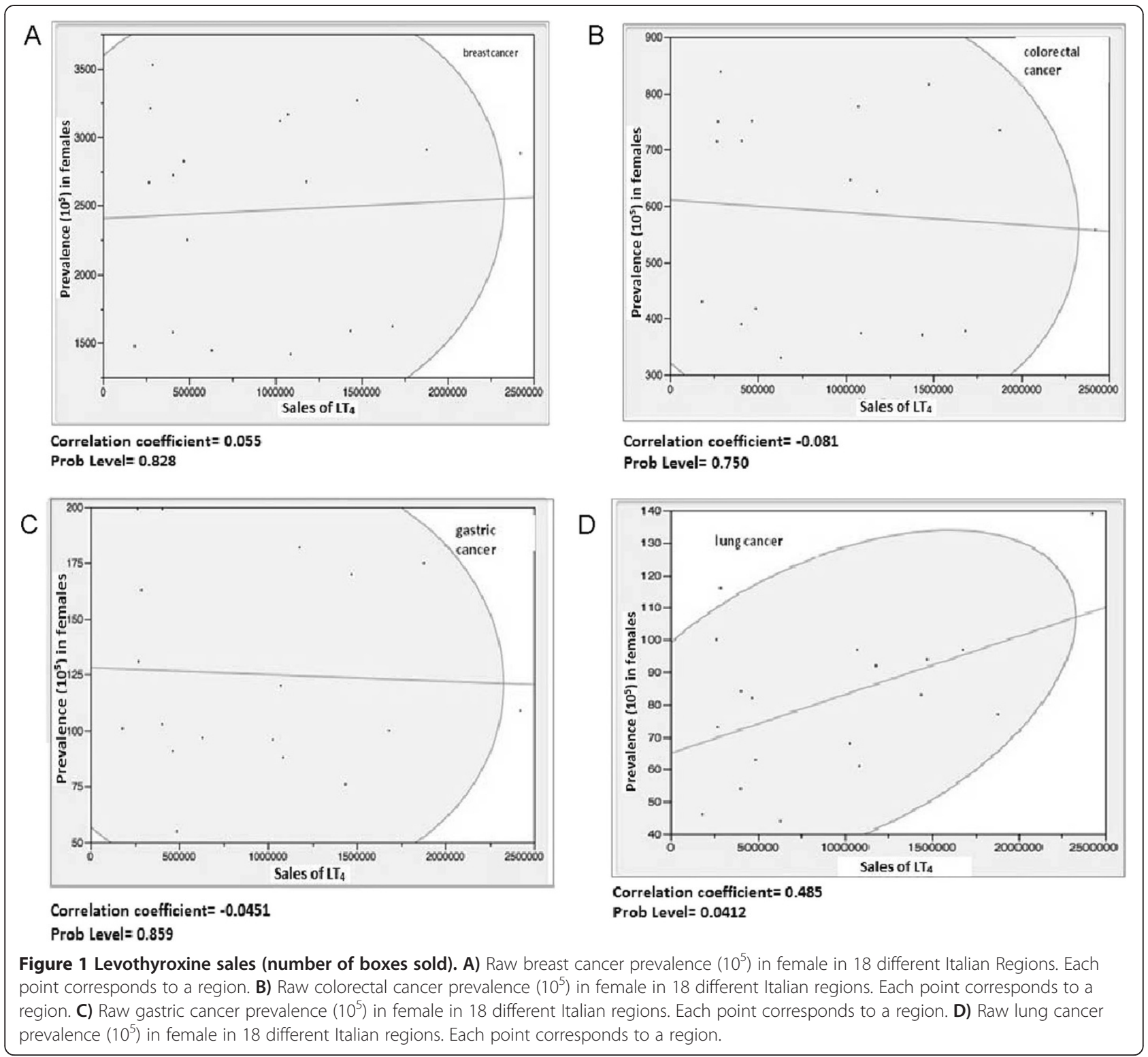

Present data do not support any relationship between $\mathrm{LT}_{4}$ and gastric cancer. In this case also the regions of Southern of Italy showed a much lower prevalence than all the other Regions (86.30 and 154.93 respectively), suggesting that the Mediterranean diet might be considered a protective tool against this cancer too.

In the Seven Country Study [12] a relationship was found between diet and stomach cancer in two Italian rural population groups. Unfortunately the study was aimed at man only, though the increase in death for gastric cancer was significantly related to high polyunsaturated fatty acid (PUFA) intake that increase oxidative stress [13].

Lung cancer was the only tumor found directly correlated with $\mathrm{LT}_{4}$ supplementation. The prevalence in
Southern Italy and the rest of the country were 73.53 and 92.89 respectively, with a far lower difference than for the other three cancers.

The importance of smoking, aging and $\mathrm{LT}_{4}$ were considered in the multivariate analysis followed by the Sequential test and showed that smoking and $\mathrm{LT}_{4}$ were much more responsible for lung cancer than aging. When smoking prevalence was eliminated by the evaluation still the relationship between $\mathrm{LT}_{4}$ and lung cancer remained significant; when similar evaluation was conducted with other type of cancer, the correlation was not significant (data not reported).

We may not exclude that the condition of hypothyroidism could favor the development of lung cancer. On the opposite it has been described recently that 
hypothyroidism reduces the aggressiveness of some cancers because of the presence of thyroid hormone receptors on cancer cells, and spontaneous hypothyroidism may delay onset or reduce aggressiveness of cancers [14]. Recently $\mathrm{LT}_{4}$ has been reported as one of the several endogenous factors capable of supporting proliferation of lung cancer cells [15]. The observation that patients with small cell carcinoma of the lung often present symptoms suggestive of hyperthyroidism (i.e. weight loss, anorexia) was made many years ago together with an over production of both $\mathrm{T}_{4}$ and $\mathrm{T}_{3}$ [16]. An old clinical observation on the relationship between lung cancer and thyroid function [17] reported that patients were characterized by a low concentration of $\mathrm{T}_{3}$ and an increased $\mathrm{T}_{4} / \mathrm{T}_{3}$ ratio due to a decrease of 5 -monodeiodination (DI). More recently DI activity in lung cancer was found to be lower than in peripheral lung tissue [18].

In experimental animals has been already shown that $\mathrm{LT}_{4}$ increases the oxidative stress [19] and spontaneous pulmonary metastases in mice [20]. Furthermore, in rats lung the deiodination of $\mathrm{LT}_{4}$ is the lowest compared to all the other tissues [21]. This means that the amount of $\mathrm{LT}_{4}$ reaching the lungs following an external supplementation cannot to be transformed into $\mathrm{LT}_{3}$ as in the other tissues, and make lungs very vulnerable to possible toxic effects of $\mathrm{LT}_{4}$.

During the therapy with $\mathrm{LT}_{4}$ even at the steady state condition a peak of the hormone is evident a couple of hours after the administration and may cause a temporary condition of hyperthyroidism and a further increase of oxidative stress.

Oxidative stress is well documented in hypothyroidism [22-24] and is even worsened through treatment with $\mathrm{LT}_{4}[1,2]$. The difference between the two conditions is that, in case of hypothyroidisms, oxidative stress is due to the reduction of $\mathrm{AO}[4]$, whereas, after the $\mathrm{LT}_{4}$ treatment it stems from overproduction of ROS from mitochondria $[5,6]$.

A very simple method that can be used to measure oxidative stress is related to hydroperoxides content in plasma which is considered a very reliable test compared to other common methods since it shows very limited coefficient of variation [25].

An inverse association with fruit and vegetables consumption and lung cancer recently has been documented recently in the EPIC study for 50 to 59 age group, without an effect on specific histological subtypes [26].

These data support the importance of the oxidative stress control in lung cancer, as was documented by the increase in urinary isoprostanes in subjects at risk of cancer in the Multiethnic Cohort Study [27].

$\mathrm{LT}_{4}$ can alter the oxidative balance in lungs and behave as a negative factor because of oxidative stress, and the condition of oxidative stress should be controlled as a routine measurement.

There should be a reason why oxidative stress taking place during the treatment with $\mathrm{LT}_{4}$ seems particularly related to lung cancer only. The hypothesis could be that in lungs the increase of hypoxia-induced factor (HIF-1) which is determined by $\mathrm{T}_{4}$ can make oxygen much more available, increasing locally the oxidative stress together with a dangerous angiogenesis stimulation [28-30].

Although we should never forget that $\mathrm{LT}_{4}$ is a life-saving thyroid hormone replacement, and that one should not exclude that the pathological reason that leads to the prescription of $\mathrm{LT}_{4}$ could favor the lung cancer development also.

However, the impression we get from our experience in epidemiological studies monitoring [31] is that this drug should be prescribed more cautiously. Considering that the population in Italy is about 60 million people and the sales of $\mathrm{LT}_{4}$ in the country in 2010 were 17.69 million boxes (+ 6\% Vs 2009), hypothyroidism, which is the main reason for the prescription, should be a real national concern (almost 0.7 boxes/women/year).

Most of the time, doctors tell patients treated with $\mathrm{LT}_{4}$ that any side effects will be temporary and almost ineluctable, and are usually dealt with through dose reduction. Assessment of oxidative stress and its balance has not been taken into consideration up to now as it should be.

Furthermore in case of oxidative stress and side effects could be important to use different type of thyroid supplementation, such as: liothyronine as well as Armour Thyroid and control the hydroperoxides levels to determine if these compounds are safer than levothyroxine.

A last comment should be made regarding the data stemming from drug sales, which are commonly used to check sales force performance and decide on marketing and sales development strategies. These data can provide extremely helpful information about the risk/benefit ratio of any drug therapy.

\section{Conclusions}

Despite the common knowledge that $\mathrm{LT}_{4}$ is a life-saving drug, some concern has to be addressed for its prescription. The findings based on the sales of $\mathrm{LT}_{4}$ in Italy are consistent with the hypothesis that there is a direct correlation between this drug and lung cancer, whereas there is no correlation with breast, colorectal and gastric cancer. However, the clinical background of hypothyroidism, which is the main reason for prescribing the drug, might also be involved in the development of lung cancer. Specific epidemiological studies should be conducted to test these two hypothesis.

This work is focused on Italian population, so it should be interesting to conduct similar studies in other regions 
of the planet and perhaps on patients of different races and subjected to different diets in order to verify if this correlation exist.

\section{Competing interests}

The authors declare that they have no competing interests.

\section{Authors' contributions}

All authors contributed to the research. All authors read and approved the final manuscript.

\section{Acknowledgments}

This work was supported by Cornelli Foundation (grant number 6). Data of levothyroxine sales were made available by IMS HEALTH.

\section{Author details}

${ }^{1}$ Loyola University School of Medicine, Chicago, USA. ${ }^{2}$ University of Chieti, Chieti, Italy. ${ }^{3}$ University of Lugano, Lugano, Switzerland. ${ }^{4}$ Cor Con International-Ox Res Dept, Parma(PR), Italy.

Received: 19 April 2013 Accepted: 24 July 2013

Published: 8 August 2013

\section{References}

1. Hennessey JV, Malabanan AO, Haugen BR, Levy EG: Adverse effect reporting in patients treated with levothyroxine: results of the pharmacovigilance task force survey of the American Thyroid Association, American Association of Clinical Endocrinologists and the Endocrine Society. Endocr Pract 2010, 16:357-370.

2. Cornelli U, Belcaro G, Ledda A, Feragalli B: Oxidative stress following administration of levothyroxine in subjects suffering from primary hypothyroidism. Pan Med 2011, 35:1-4.

3. Cornelli U, Belcaro G, Ledda A, Feragalli B: Activity of some physiological modulators in reducing the side effects of levothyroxine in patients suffering from primary hypothyroidism. Pan Med 2011, 35:5-9.

4. Cetinkaya A, Kurutas EB, Buyukbese MA, Kantarceken B, Bulbuloglu E: Levels of malondialdehyde and superoxide dismutase in subclinical hyperthyroidism. Med Inflamm 2005, 1:57-59.

5. Fernandez V, Tapia G, Varela P, Romanque P, Cartier-Ugarte D, Videla LA: Thyroid hormone-induced oxidative stress in rodents and humans: a comparative view and relation to redox regulation of gene expression. Comp Biochem Physiol C Toxicol Pharmacol 2006, 142:231-239.

6. Venditti P, Di Meo S: Thyroid hormone-induced oxidative stress. Cell Mol Life Sci 2006, 63:414-434.

7. Bencivenga S, Bartolone L, Pappalardo MA, Russo A, Lapa D, Giorgianni G, Saraceno G, Trimarchi F: Altered intestinal absorption of L-thyroxine caused by coffee. Thyroid 2008, 18:293-301.

8. Russell W, Harrison RF, Smith N, Darzy K, Shalet S, Weetman AP, Ross RJ: Free triiodothyronine has a distinct circadian rhythm that is delayed but parallels thyrotropin levels. J Clin Endocrinol Metab 2008, 93:2300-2306.

9. Wonnacott TH, Wonnacott RJ (Eds): Regression: a second course in statistics. Lund, Sweden: John Wiley and Sons; 1981

10. Rossner P, Gammon MD, Terry MB, Agrawal M, Zhang FF, Teitelbaum SL, Eng SM, Gaudet MM, Neugut Al, Santella RM: Relationship between urinary 15-F2 t-isoprostane and 8-oxodeoxyguanosine levels and breast cancer. Cancer Epidemiol Biomarkers Prev 2006, 15:639-644.

11. Rennet G, Rennert HS, Pinchev M, Gruber SB: A case control study of levothyroxine and risk of colorectal cancer. J Natl Cancer Inst 2010, 102:568-572.

12. Farchi G, Mariotti S, Menotti A, Seccareccia F, Torsello S, Fidanza F: Diet and 20-y mortality in two rural population groups of middle-aged men in Italy. Am J Clin Nutr 1989, 50:1095-1103.

13. Filaire E, Massart A, Rouveix M, Portier H, Rosado F, Durand D: Effect of 6 weeks of $n-3$ fatty acids and antioxidant mixture on lipid peroxidation at rest and post-exercise. Eur J Appl Physiol 2011, 111:1829-1839.

14. Hercbergs AH, Ashur-Fabian O, Garfield D: Thyroid hormone and cancer: clinical studies of hypothyroidism in oncology. Curr Opin Endocrinol Diabetes Obes 2010, 17:432-436.

15. Meng R, Tang HY, Westfall J, London D, Cao JH, Mousa SA, Luidens M, Hercbergs A, Davis FB, Davis PJ, et al: Crosstalk between integrin av $\beta 3$ and estrogen receptor- $a$ is involved in thyroid hormone-induced proliferation in human lung carcinoma cells. PLoSone 2011, 11:e27547.

16. Faber J, Poulsen S, Iversen P, Kirkegaard C: Thyroid hormone turnover in patients with small cell carcinoma of the lung. Acta Endocrinol 1988, 118:460-464.

17. Ratcliffe JG, Stack BH, Burt RW, Radcliffe WA, Spilg WG, Cuthbert J, Kennedy RS: Thyroid function in lung cancer. Brit Med J 1978, 1:210-212.

18. Wawrzynska L, Sakowicz A, Rudzinski P, Langfort R, Kurzyna M: The conversion to triiodothyronine in the lung: comparison of activity of type I iodotironine $5^{\prime}$ deiodinase in lung cancer with peripheral lung tissues. Monaldi Arch Chest Dis 2003, 59:140-145.

19. Venditti P, Di Stefano L, Di Meo S: Oxidative stress in cold induced hyperthyroid state. J Exp Biol 2010, 213:2899-2911.

20. Kinoshita S, Sone S, Yamashita T, Tsubura E, Ogura T: Effects of experimental hyper-and hypothyroidism on natural defense activities against Lewis lung carcinoma and its spontaneous pulmonary metastases in C57BL/6 mice. Tokushima J Exp Med 1991, 38:25-35.

21. van Doorn J, Roelfsema F, van der Heide D: Concentration of thyroxine and 3,5,3'-triiodotyronine in several rat tissue in vivo: the effect of hypothyroidism. Endocrinology 1985, 117:1201-1208.

22. Nanda N, Bobby Z, Hamide A: Oxidative stress and protein glycation in primary hypothyroidism. Male/Female difference. Clin Exp Med 2008 8:101-108.

23. Erdemar H, Demirci H, Yaman H, Erbil MK, Yakar T, Sancak B, Elbeg S, Biberoğlu G, Yetkin I: The effect of hypothyroidism, hyperthyroidism, and their treatment on parameters of oxidative stress and antioxidant status. Clin Chem Lab Med 2008, 46:1004-1010.

24. Costantini F, Pierdomenico SD, De Cesare D, De Remigis P, Bucciarelli T, Bittolo-Bon G, Cazzolato G, Nubile G, Guagnano MT, Sensi S, et al: Effect of thyroid function on LDL oxidation. Atheroscler Throm Vasc Biol 1998, 18:732-737.

25. Cornelli U, Belcaro G, Finco A: The oxidative stress balance measured in humans with different markers, following a single oral antioxidants supplementation or a diet poor of antioxidants. J Chem Dermatol Sci Appl 2011, 1:64-70

26. Büchner FL, Bueno-de-Mesquita HB, Linseisen J, Boshuizen HC, Kiemeney LA, Ros MM, Overvad K, Hansen L, Tjonneland A, Raaschou-Nielsen O, et al: Fruits and vegetables consumption and the risk of histological subtypes of lung cancer in the European Prospective Investigation into Cancer and Nutrition (EPIC). Cancer Causes Control 2010, 21:357-371.

27. Epplein M, Franke AA, Cooney RV, Morris JS, Wilkens LR, Goodman MT, Murphy SP, Henderson BE, Kolonel LN, Le Marchand L: Association of plasma micronutrients levels and urinary isoprostane with risk of lung cancer: the multiethnic cohort study. Cancer Epidemiol Biomarkers Prev 2009, 18:1962-1970.

28. Otto T, Fandrey J: Thyroid hormone induces hypoxia-inducible factor $1 \mathrm{a}$ gene expression through thyroid hormone receptor $\beta /$ retinoid $x$ receptor $\alpha$-dependent activation of hepatic leukemia factor. Endocrinology 2008, 149:2241-2250.

29. Hofer T, Desbaillets I, Höpfl G, Wenger RH, Gassmann M: Characterization of HIFD-1 alpha overexpressing Hela cells and implication for gene therapy. Comp Biochem Physiol C Toxicol Pharmacol 2002, 133:475-481.

30. Wan J, Chai H, Yu Z, Ge W, Kang N, Xia W, Che Y: H1F-1a on angiogenic potential in human small cell carcinoma. Clin Cancer Res 2011, 30:77.

31. Cesarone MR, Belcaro G, Nicolaides AN, Incandela L, De Sanctis MT, Barsotti A San Valentino epidemiologic project. Angiology 2000, 51:S65-S68.

\section{doi:10.1186/1477-7827-11-75}

Cite this article as: Cornelli et al.: Levothyroxine and lung cancer in females: the importance of oxidative stress. Reproductive Biology and Endocrinology 2013 11:75. 